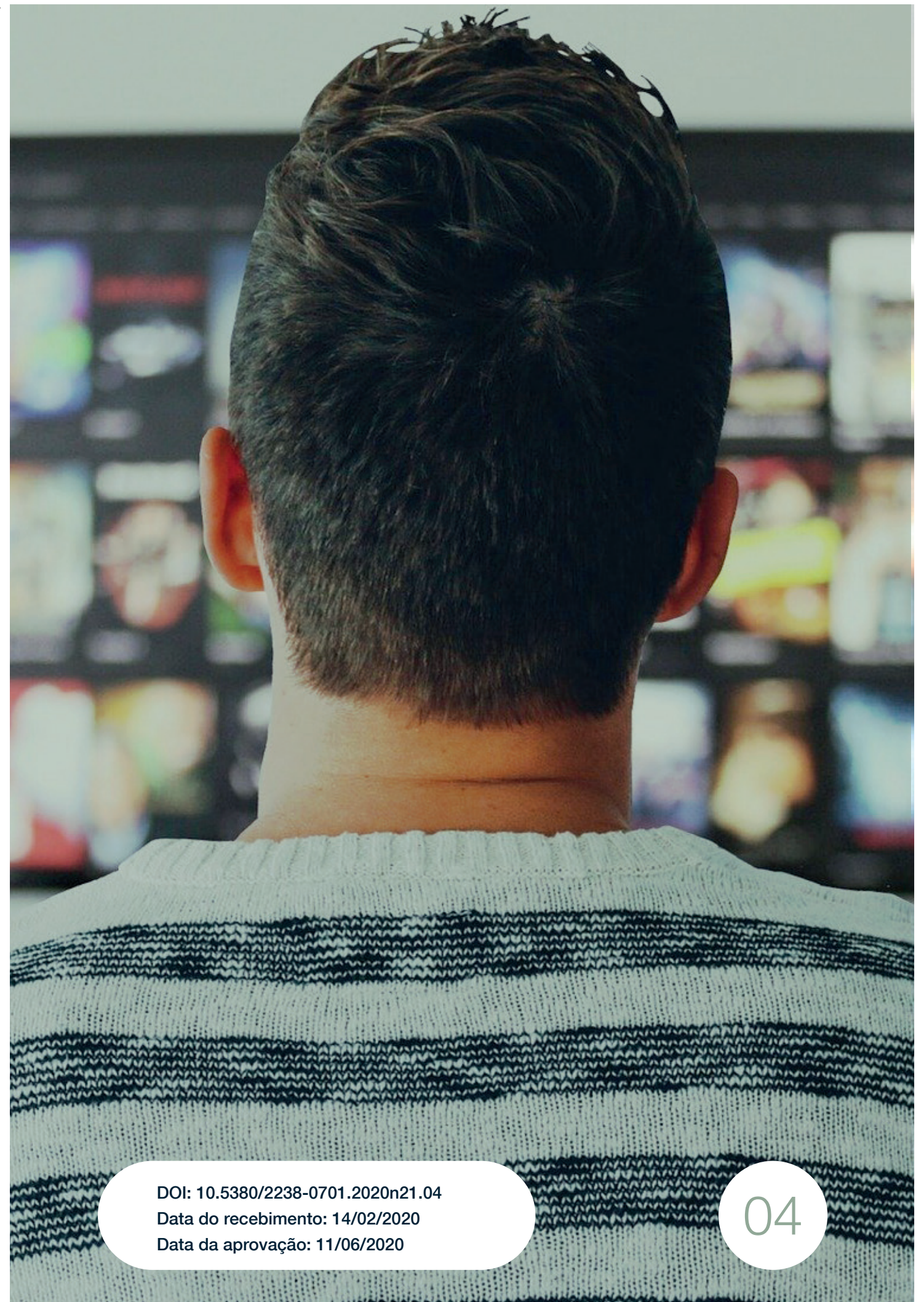

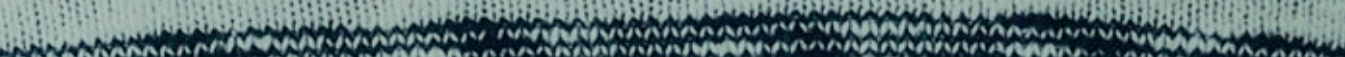


Modelos em disputa: Uma análise dos lugares da Netflix e da HBO no campo da produção audiovisual 


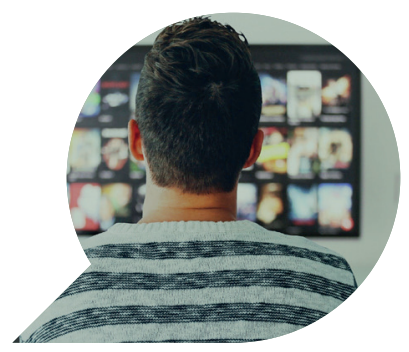

\title{
Modelos em disputa: Uma análise dos lugares da Netflix e da HBO no campo da produção audiovisual
}

\author{
Models in dispute: An analysis of Netflix and HBO's \\ places in the field of audiovisual production
}

Modelos en disputa: Un análisis de los lugares de Netflix y HBO en el campo de la producción audiovisual

CAROLINA SANTOS FAGUNDES ${ }^{1}$

TATIANA GUENAGA ANEAS²

Resumo: O presente artigo apresenta uma reflexão sobre o estado atual do campo da produção televisiva, tendo em vista as transformações ensejadas pela cultura digital e pelo uso do streaming na criação, distribuição e consumo de conteúdos audiovisuais. Considera-se, nesta perspectiva, que do ponto de vista tecnológico o momento presente reflete um embate entre o modelo outrora dominante do broadcasting e um modo de produção em vias de consolidação do streaming. Para o campo televisivo, significa

\footnotetext{
1 Graduada em Comunicação Social: Publicidade e Propaganda pela Universidade Federal de Sergipe. Mestranda do PPGCOM na Universidade Federal de Sergipe.

2 Professora adjunta II do Departamento de Comunicação, membro permanente do Programa de Pós-graduação Interdisciplinar em Cinema e do Programa de Pós-graduação em Comunicação da Universidade Federal de Sergipe. Líder do Lavint - Laboratório de Análise em Visualidades, Narrativas e Tecnologia. Doutora em Comunicação e Cultura Contemporâneas pelo Póscom/Universidade Federal da Bahia (2016). Mestre em Comunicação e Cultura Contemporâneas pela mesma instituição (2011). Graduada em Comunicação Social com habilitação em Jornalismo pela Universidade Federal da Bahia (2007).
} 
uma mudança processual na lógica de sustentação econômica e reconhecimento social de seus agentes e instituições. Para demonstrar tais premissas, propõe-se um exercício de análise comparativa das trajetórias da HBO e da Netflix apoiado sobretudo na teoria dos campos.

Palavras-chave: Netflix, HBO, streaming, broadcasting, campo.

Abstract: This article presents a reflection on the current state of the field of television production because of the transformations brought about by digital culture and the use of streaming in the creation, distribution, and consumption of audiovisual content. From this perspective, it's considered that, from a technological point of view, the present moment reflects a clash between the once-dominant model of broadcasting and a mode of production in the process of consolidating streaming. For the television field, it means a procedural change in the logic of economic support and social recognition of its agents and institutions. To demonstrate these premises, we propose an exercise in a comparative analysis of the trajectories of $\mathrm{HBO}$ and Netflix based mainly on the theory of the fields.

Keywords: Netflix; HBO; Streaming; Broadcasting; Field.

Resumen: Este artículo presenta una reflexión sobre el estado actual del campo de la producción televisiva, en vista de las transformaciones provocadas por la cultura digital y el uso de la transmisión en la creación, distribución y consumo de contenido audiovisual. En esta perspectiva, se considera que, desde un punto de vista tecnológico, el momento presente refleja un choque entre el modelo de transmisión que alguna vez fue dominante y un modo de producción en el proceso de consolidación de la transmisión. Para el campo de la televisión, significa un cambio de procedimiento en la lógica del apoyo económico y el reconocimiento social de sus agentes e instituciones. Para demostrar estas premisas, proponemos un ejercicio de análisis comparativo de las trayectorias de $\mathrm{HBO}$ y Netflix basado principalmente en la teoría de los campos.

Palabras clave: Netflix, HBO, transmisión, transmisión, campo. 
Na última década, observa-se uma expansão considerável do consumo de produtos audiovisuais através da tecnologia de streaming ${ }^{3}$, alterando significativamente o campo da produção audiovisual em todo o mundo. Neste contexto, novas empresas e agentes que se utilizam do streaming ascendem a posições dominantes, em parte pelo reconhecimento social pela inovação na criação de obras audiovisuais, sobretudo séries e filmes, mas também pelo acúmulo de capital econômico decorrente do êxito do modelo de negócios adotado. De outro lado, grupos, agentes e instituições que ao longo do tempo se consolidaram neste campo através do modelo de broadcasting disputam por sua permanência num lugar de poder. Considerando-se este panorama, observa-se que a Netflix pode ser tomada como caso exemplar do grupo de empresas que investem em uma transfiguração do campo televisivo como era conhecido até meados dos anos 2000, e que hoje ocupa ou, ao menos, disputa uma posição outrora hegemonicamente dominado por emissoras de broadcasting. Desde 1997, a empresa estadunidense fundada por Reed Hastings passou de locadora de DVDs online para a posição de expressiva produtora de conteúdo audiovisual do mundo, com mais de 150 milhões de assinantes. Na base desta trajetória ascendente encontra-se a adoção de estratégias alinhadas à cultura digital, no contexto da indústria criativa, como a oferta de conteúdo on demand, a produção voltada para nichos de consumo e o uso de big data para a formulação de sistemas de recomendação. Em paralelo, é notório que a empresa busca posicionar-se neste campo em um lugar de reconhecimento pela qualidade das suas obras, o que pode ser observado pelo menos desde o lançamento da série House of $\mathrm{Cards}^{4}$, série vencedora de prêmios como Emmy e Golden Globes, e que segue sendo uma prática visível em produções de autores consagrados no campo do cinema e do audiovisual disponibilizadas e assinadas pela plataforma.

Ao longo da história do campo televisivo, entretanto, observamos que a Netflix não é a primeira a procurar construir uma posição a partir da qual se é reconhecida pela inovação e qualidade de suas obras. Isso

\footnotetext{
3 Em estudo divulgado pela Associação de Cinema dos Estados Unidos (MPAA) no ano de 2019, foi observado o crescimento do entretenimento audiovisual no ano de 2018: os resultados positivos foram atribuídos ao crescimento das plataformas de streaming de vídeos que, na ocasião, haviam atingido a marca de 613 milhões de assinantes, superando, por exemplo, o número de assinantes da TV a cabo. 4 House Of Cards é uma série original lançada pela Netflix em 2013. Sua história gira em torno das relações de poder no campo político dos Estados Unidos através da história do casal Francis e Claire Underwood.
} 
porque, em momento anterior, quando a oferta de obras audiovisuais na televisão estava sustentada por produtos criados sob a égide da repetição (ECO, 1989), a HBO será identificada como responsável por uma mudança na lógica do modelo de produção e distribuição então vigente. Ao longo de sua trajetória, a empresa de TV por assinatura investiu em produtos mais elaborados do ponto de vista narrativo e estético, num movimento conhecido pelo mercado como quality $T V$, e sinalizado por autores como Mittel (2006), através da noção de complexidade narrativa televisiva.

É mister notar, entretanto, que tal estratégia não é inaugurada pela $\mathrm{HBO}$, uma vez que já podia ser observada em produções anteriores do sistema aberto de televisão nos Estados Unidos, tais como as séries Twin Peaks, Grey's Anatomye Lost, produzidas pela ABC. Neste trabalho, porém, o foco de análise recai sobre a trajetória da Netflix, sem deixar de discernir o espaço de possíveis previsto na própria história do campo na qual a empresa se insere. Espera-se, assim, alcançar uma compreensão sobre como, por um lado, a produtora de conteúdo induz este campo a operar sob uma lógica diferente, ao mesmo tempo em que parte de práticas anteriormente consolidadas. Para tanto, é convocada uma perspectiva teórico-metodológica baseada sobretudo na teoria dos campos (BOURDIEU, 1992, 1996), bem como em autores que aproximam a perspectiva do autor do campo da produção cultural e televisiva, a exemplo de Souza (2005) e Bianchinni (2011). Articulam-se, ainda, noções da cultura digital para pensar o audiovisual (SANTAELLA, 2003; MURRAY, 2003); e da indústria criativa, sobretudo através do trabalho de Florida (2011). Por fim, propõe-se um exercício de análise da trajetória da Netflix atravessado por este olhar, com o objetivo de lançar luz sobre os motivos do seu sucesso relativo neste campo em específico.

\section{Premissas teórico-metodológicas}

Apresentam-se aqui as premissas teórico-metodológicas que fundamentam este trabalho, bem como os conceitos que servirão de operadores para o exercício de análise proposto. Neste sentido, o principal alicerce encontra-se na sociologia da cultura segundo a perspectiva de Bourdieu (1992, 1996), sobretudo através dos conceitos de campo, ca- 
pitais (econômico, cultural, simbólico, social), habitus e trajetória social. Interessa, sobretudo, uma leitura do pensamento bourdiano que procura compreender as práticas dos produtores culturais como resultado e, ao mesmo tempo, estruturantes do seu conjunto de possibilidades de ação. Neste sentido, compreende-se o conceito de campo social como um espaço de concorrência destes agentes pelos capitais que são ali relevantes e cuja posse conduz às posições privilegiadas, a partir das quais se pode influenciar as regras de funcionamento deste universo. Munidos desta forma de olhar, é possível interpretar as mudanças que se operam nos campos para além das determinações externas, de ordem puramente econômica, política, tecnológica, etc. Nos termos do autor:

O motor da mudança nas obras culturais, na língua, na arte, na literatura, na ciência etc., reside nas lutas cujo lugar são os campos de produção correspondentes: essas lutas que visam a conservar ou a transformar as relações de força instituídas no campo de produção têm, evidentemente, o efeito de conservar, ou de transformar, a estrutura do campo das formas que são instrumentos alvos nessas lutas (BOURDIEU, 1996, p. 63).

Tal perspectiva não é adotada sem que se constatem as ingerências externas, sobretudo do poder econômico, no que diz respeito às contingências de ação dos produtores de obras audiovisuais televisivas. Dito de outro modo, reconhece-se que o campo da produção televisiva é atravessado pela lógica comercial, pelo imperativo do lucro, sem que isso signifique ausência de margem para criação original e inovação. Neste sentido, Souza afirma, a respeito do campo de produção de telenovelas no Brasil:

O universo de práticas que envolvem as telenovelas, com certeza, não diz respeito ao palco das posturas que definem estas obras a partir da recusa do econômico. Entretanto, observa-se no campo da telenovela uma forte preocupação dos agentes em definir e buscar a qualidade artística em função de um "projeto criador" que os anima, apesar de saberem da força limitadora do econômico na sua constituição. (SOUZA, 2005, s. p.).

É com este espírito que este trabalho pretende apresentar a história da Netflix, lançando luz sobre aspectos contextuais que colaboram com a sua trajetória. O termo é aqui convocado como operador de análise, compreendido como as diferentes posições ocupadas pela empresa no seu campo, "uma maneira singular de percorrer o espaço social, onde 
se exprimem as disposições dos habitus" (BOURDIEU, 1992, p. 292) e que está relacionada, por um lado, com o espaço de possíveis historicamente constituído e, por outro, com as disputas do(s) momento(s) examinado(s). Entendida como a sucessão de posições ocupadas no espaço social por um grupo ou agente nele atuante, esta noção imprescinde do conhecimento do campo no qual esta trajetória se constrói, uma vez que "é com relação aos estados correspondentes da estrutura do campo que se determinam o sentido e o valor dos acontecimentos biográficos, entendidos como colocações e deslocamentos neste espaço" (1996, p. 292). O próprio termo trajetória deixa claro o fato de que o percurso de um profissional ou empresa dentro de um campo de produção não é imune às forças sociais que nele estão em jogo em dado momento. É por esse motivo, pela premissa de uma interpretação relacional, que faz-se necessária a comparação, ao menos, com a trajetória da HBO - sem deixar de admitir que outras empresas e instituições podem se somar a esta análise, que aqui se abrevia em decorrência dos limite de um artigo científico.

Por fim, importa esclarecer de que maneira as noções de capitais colaboram para a compreensão do fenômeno aqui estudado, centralmente, a de capital econômico e capital simbólico. Considerando que a produção televisiva contemporânea é capitaneada por empresas sejam elas produtoras, programadoras, empacotadoras, baseadas em modelos de negócios tradicionais ou startups - é evidente que há que se considerar o capital econômico, representado em indicadores como faturamento, lucro, audiência, número de assinantes, entre outros, como definidor da sua posição no campo. De outro lado, há também que se considerar aquilo que Bourdieu chama de capital simbólico, a saber, o reconhecimento atribuído pelos pares através de premiações, rankings, da crítica e outras instâncias de consagração. Considera-se que as experiências mais bem-sucedidas neste campo são aquelas que tendem a articular o acúmulo dos dois tipos de capitais, como será demonstrado mais adiante. No caso específico da Netflix, procura-se demonstrar como a inovação enquanto estratégia de ação está presente, por um lado, no modelo de negócios, acarretando ganhos econômicos e, por outro, nas suas obras audiovisuais, do que decorre seu relativo prestígio e reconhecimento social. E, também, que essa posição foi possibilitada pela existência prévia de um espaço constituído por outras empresas, como a HBO. 


\section{Cultura da televisão, cultura digital e indústrias criativas}

Ao longo de sua história, a televisão passou por diversas etapas para que pudesse se desenvolver. Bianchini (2011) define basicamente três eras: Era da TV I, que durou aproximadamente dos anos 1940 a 1970; Era da TV II, que dura do fim dos anos 1970 até o início da década de 1990; Era da TV III, que abarca dos anos 1990 até meados dos anos 2000. Como observado por Bianchini (2011, p. 22), a Era da TV I se caracteriza pelo período em que foram institucionalizadas as práticas de criação, produção, distribuição e consumo que caracterizam os primeiros anos da história do meio televisivo, além de marcar o domínio das grandes redes de televisão ABC, CBS e NBC. A Era da TV II é marcada pela popularização da TV por assinatura, das estratégias de produção para nichos e consequente ampliação de opções de consumo para os telespectadores. Já o período da Era da TV III é representado por novas formas de acesso ao conteúdo ensejadas pela emergência da cultura digital, além de ressaltar a importância do marketing para as estratégias de divulgação e fortalecimento, bem como o posicionamento de marcas do meio televisivo através do brand marketing (Bianchini, 2011, p. 39).

No campo de produção audiovisual atual, ainda é possível observar a força do modelo tradicional de produção e distribuição, o broadcasting, que é utilizado, em especial, por emissoras de televisão, abertas e fechadas. É dentro deste modelo que a HBO (Home Box Office) foi criada e tornou-se um importante expoente no campo televisivo no cenário mundial, prestígio alcançado através do sucesso de títulos como The Sopranos, Sex And The City e Game of Thrones ${ }^{5}$, esta última considerada produto de maior retorno em audiência para a empresa. Com suas produções, a emissora, que integra o grupo Warner Media, atingiu uma posição de destaque entre a crítica, sendo presença constante nas listas de vencedores de premiações como o Emmy Awards, no qual só no ano de 2019 a empresa faturou 34 prêmios, sendo a mais premiada da edição. A posição de destaque alcançada pelo canal pode ser atribuída a suas estratégias, não apenas à criação de uma programação estável através de séries com alto investimento, autonomia e liberdade criativa

5 Game Of Thrones é uma série de televisão, baseada na obra literária de George R.R. Martin, lançada em 2011 pela HBO. Após seis temporadas, a obra chegou ao fim em episódio assistido por 19,3 milhões de pessoas. Com essa marca, superou o recorde de transmissão mais assistida da HBO, alcançado por "The Sopranos" em 2002, quando a série foi vista por 18,2 milhões de pessoas. 
ao mesmo tempo em que trabalhava no fortalecimento de sua marca, que busca se posicionar como símbolo de qualidade, através do slogan "It's Not TV. It's HBO" (Bianchinni, 2011).

Em paralelo à existência do modelo tradicional de produção televisiva, baseado em transmissão de larga escala, a emergência da tecnologia digital e de novas formas sociais e culturais por ela propiciadas está na base material de experiências como a da Netflix.

Ao mesmo tempo, novas sementes começaram a brotar no campo das mídias com o surgimento de equipamentos e dispositivos que possibilitaram o aparecimento de uma cultura do disponível e do transitório: fotocopiadoras, videocassetes e aparelhos para gravação de vídeos, equipamentos do tipo walkman e walktalk, acompanhados de uma remarcável indústria de videoclipes e videogames, juntamente com a expansiva indústria de filmes em vídeo para serem alugados nas videolocadoras, tudo isso culminando no surgimento da TV a cabo. Essas tecnologias, equipamentos e as linguagens criadas para circularem neles têm como principal característica propiciar a escolha e consumo individualizados, em oposição ao consumo massivo. (SANTAELLA, 2003, p. 26).

Trazendo o pensamento da autora para a contemporaneidade, pode-se pensar o fenômeno da produção e consumo audiovisual por demanda via streaming como uma extensão deste processo, que se inicia com a cultura das mídias e se estabelece com a cultura digital. Como observado por Wolff (2015), outrossim, mais do que trazer o digital para a televisão, o serviço insere a cultura da televisão no digital, a partir do desenvolvimento de novos costumes e preferências do consumidor que são também moldados pelas possibilidades emergentes de produção e distribuição de conteúdo audiovisual televisivo no ambiente digital.

A possibilidade de um serviço como a Netflix está assentada não apenas nos recursos tecnológicos, como também na mudança de comportamento do consumidor, como observa Murray (2003). O consumo de audiovisual é ora ubíquo e multidispositivo, o que favorece formas de se relacionar com os conteúdos que se afastam do modelo tradicional da grade televisiva. Tal contexto faz emergir fenômenos como o binge watching e um assistir TV socialmente compartilhado e ressignificado através de redes sociais digitais.

Os moldes da arte narrativa e do entretenimento nas próximas décadas serão determinados pela interação dessas duas forças, isto é, entre os experimentadores mais ágeis e independentes, que se 
sentem à vontade com o hipertexto e os conglomerados gigantes da indústria do entretenimento que possuem recursos imensos e uma conexão já estabelecida com o grande público (MURRAY, 2003, p. 236).

Ainda no que tange às consequências da cultura digital, importa destacar os processos de datificação e plataformização (VAN DIJCK, POELL, DE WALL, 2018) que subjazem à experiência da Netflix, mormente no que tange à utilização de grandes dados. De acordo com Taurion (2013), big data é uma combinação de volume, variedade, velocidade e veracidade dos dados, aspectos que, combinados, levam à geração de valor. O volume está ligado à quantidade de dados disponíveis que são gerados no meio digital através de sistemas estruturados e não estruturados como redes sociais, cadastros, e-mails, buscas, etc. A variedade é importante para que haja dados suficientes para serem cruzados e que possam gerar análises relevantes acerca do usuário; a velocidade está ligada à necessidade de agir em tempo real, para que a organização possa ter uma vantagem competitiva; a veracidade está na necessidade de saber se os dados produzidos são realmente relevantes e se irão de fato produzir valor para a empresa. É sabido que a Netflix utiliza, de forma pioneira no campo da produção audiovisual, dados de consumo gerados pela plataforma que orientam as tomadas de decisão em vários aspectos do negócio, inclusive criativos, influenciando na escolha de temas para as produções, elenco e país de origem dos produtos, dentre outros.

Neste ponto, é possível também refletir acerca da importância de situar a empresa na chamada economia criativa, que se dá, entre outros fatores, através da ascensão da classe criativa, como explicado por Florida (2011, p. 44). O autor defende que a expansão conjunta de inovação tecnológica e trabalho de conteúdo criativo é cada vez mais a força motriz do crescimento econômico e alerta para o fato de que a ascensão da economia que tem a criatividade como vetor gerou novos modelos sociais e econômicos. Por outro lado, grandes empresas ainda desempenham papéis predominantes na indústria e, ainda que tenham adotado ou sido criadas com políticas internas que possam ser mais inclusivas, ágeis e flexíveis, elas ainda são instituições burocráticas. Sendo a Netflix uma empresa que explora o entretenimento audiovisual, pode-se apontar que seu negócio depende da contribuição da classe criativa, desde o insight que levou os fundadores a criar uma empresa que oferece um 
serviço que se diferencia dos modelos até então conhecidos, passando por sua estratégia de divulgação nos dias atuais e, principalmente, pelos produtos que são oferecidos, suas produções audiovisuais. Entretanto, como uma empresa inserida em um sistema capitalista, a Netflix busca aliar inovação e lucro, ou ainda, adota um modelo de negócios e uma cultura de produção baseada no risco. Para isso, utilizando-se sobretudo do uso de dados gerados pela própria interação na plataforma, a empresa investe no conhecimento sobre o consumidor e a experiência de consumo, adotando estratégias como curadoria, recomendação, personalização e segmentação - esta última não apenas na oferta, mas na própria produção das obras, como já dito. Ainda na perspectiva de Florida (2011), por mais que um indivíduo criativo possa atuar independentemente, numa parte considerativa das vezes ele ainda depende da ação de uma grande empresa, ou de um agente com maiores recursos, para investir em sua criação caso tenha como objetivo levá-la a outro patamar. Isso pode ser exemplificado com o processo de compra e produção de conteúdo original, observada nos lançamentos diferenciados da Netflix ou mesmo nas apostas pelos pilotos de produção dentro das emissoras do broadcasting.

Assentando possíveis: o lugar da HBO no campo televisivo

Entender o lugar da Netflix no campo da produção audiovisual televisiva, como dito, imprescinde de compreender como este espaço em que a empresa se insere chegou a um estado que permitiu sua existência. Argumenta-se aqui que compreender parte da trajetória da HBO pode ajudar a iluminar aspectos que seriam posteriormente fundamentais neste sentido. Fundada em 1972 como subsidiária da Time, posteriormente Time Warner, foi a partir dos anos 1990 que a emissora de TV por assinatura passou a ser reconhecida como produtora de "Quality TV" (KELSON, 2008), com o lançamento de séries como The Sopranos, movimento que interessa sobremaneira este trabalho, posto que é onde se encontram as bases que tornaram possíveis, posteriormente, o surgimento da Netflix. Destacam-se, neste contexto, três aspectos centrais da posição da HBO no campo televisivo da década de 1990 nos quais é possível observar uma ruptura e que estarão também presentes na empresa de streaming: o modelo de negócios, a comunicação e a produção de conteúdo.

No que diz respeito ao modelo de negócios, a HBO distingue-se das 
redes de TV aberta e da maioria dos seus concorrentes por não depender da veiculação de anúncios publicitários. A fonte principal de faturamento da empresa era então quase exclusivamente as assinaturas. Diferentemente das networks, que vendem a atenção dos telespectadores para os anunciantes, o modelo de comercialização da HBO é baseado na oferta direta de conteúdo para seus assinantes, deixando a empresa relativamente independente dos índices de audiência (SANTO, 2008). Este modelo oportuniza à empresa ter maior liberdade criativa, já que não tem como imposição a necessidade de criar um contexto de consumo favorável aos anunciantes (KELSO, 2008), bem como não a leva a se preocupar com o eventual fracasso de um programa específico, já que a assinatura inclui um pacote de programação.

No que tange à comunicação, entende-se que o posicionamento adotado, representado sobretudo no slogan "It's not TV, it's HBO", foi essencial para que a HBO marcasse lugar neste universo através de uma estratégia de distinção. Para Edgerton (2008), os canais que se denominavam premium precisavam desenvolver uma forte identidade para que pudessem se diferenciar das emissoras da TV aberta e dos outros canais pagos. Santo (2008) argumenta que, com esta estratégia, a HBO se posiciona em um lugar a partir do qual seus assinantes têm uma promessa de acesso a um capital cultural exclusivo, "[...] separados das massas que devem se contentar em 'assistir TV6'" (SANTO, 2008, p. 32). É uma forma de diferenciar sua programação e, também, seu público, vendendo, além do entretenimento, uma oportunidade de o telespectador se distinguir socialmente. Pode-se aqui fazer alusão às noções de "grande produção" e "produção restrita", discutidas por Bourdieu (1992) a despeito do campo literário francês e nas quais a "qualidade social do público" (1992, p. 135) é um indicador importante destas posições.

Embora afirme que o que faz "não é televisão", está claro que a empresa continua inserida no campo da produção audiovisual televisiva, devendo sua posição a uma negação daquilo que se entende tradicionalmente como TV. Com esta tomada de posição, não apenas no plano do discurso, mas sobretudo nas práticas de produção de conteúdo, pautadas pela relativa inovação e pelo risco como lógica empresarial (KELSO, 2008, p. 49), a HBO induz uma alteração neste campo, que orientará a ação de outras empresas, tais como AMC e Showtime, e

6 [...] separates them from the masses who must settle for "must see TV" (tradução nossa). 
mesmo emissoras abertas como ABC e Fox, que posteriormente passam a investir com mais frequência em produção original de ficção seriada qualificada, levando a fórmula da "quality TV" para o mainstream, como apontaram McCabe e Akass (2008, p. 91). Os marcadores de qualidade podem ser identificados na estética dos produtos, com o uso de convenções do cinema (uma "arte" então já reconhecida como tal), na inovação narrativa e nas produções autorais. Tratam-se de valores que, conforme argumenta Santo (2008), fazem parte da cultura produtiva da empresa e que imprimiram mudanças na lógica de funcionamento do campo, anteriores ao surgimento da Netflix, mas que serão fundamentais para sua emergência e a consolidação.

Como observado por Florida (2011), o fato de uma empresa ser tradicional ou existir há muito tempo não a torna parte da "velha economia", tampouco a impede de acompanhar as tendências dentro do seu campo de atuação. Assim, o canal já busca se fazer presente no streaming através do aplicativo, HBO Go, além de disponibilizar seu conteúdo para plataformas como o Claro NET NOW, acessado por clientes da operadora de TV Claro NET. O próximo passo da HBO é o lançamento da plataforma de streaming HBO Max, que contará com todo conteúdo da emissora exibido através do broadcasting, além de títulos da Warner Bros, DC Comics, Cartoon Network colocando a empresa em um cenário de disputa em que, além da Netflix como concorrência, aparecem outras empresas, tais como Disney +, Apple TV, Amazon Prime etc.

\section{A trajetória da Netflix}

A trajetória da Netflix começa em 1997, pelas mãos dos empreendedores Reed Hastings e Marc Rudolph, que ao perceberem que a relação entre o serviço prestado pelas locadoras e o consumidor estava defasada, criam um serviço com a proposta de distribuir conteúdo audiovisual ao consumidor com a praticidade de fazer a solicitação e receber o serviço em casa sem custos adicionais, contrapondo-se ao serviço prestado pelas tradicionais locadoras. Posteriormente, a empresa criada por Hastings e Rudolph se tornou referência no campo do entretenimento audiovisual ao apostar no streaming como modelo de distribuição, com um modelo de assinatura mensal que oferece aos clientes um catálogo 
repleto de títulos licenciados, além de conteúdo original exclusivo produzido baseando-se nos dados obtidos pela base de assinantes que, de acordo com os números divulgados em 2019, mostram que a Netflix conta com mais de 150 milhões de clientes mundialmente.

Até a Netflix, a televisão sempre fora organizada em um modelo geográfico. As redes eram uma associação de afiliados locais; até os mais consolidados sistemas a cabo eram uma coletânea de licenças exclusivas para cabear comunidades específicas; estações de TV a cabo sobreviviam ou pereciam, o que dependia de suas habilidades de negociar com franquias locais. E, obviamente, nada disso transcendia as fronteiras nacionais. A Netflix, por outro lado, implantou seu serviço de streaming - inicialmente com uma licença de conteúdo da Starz, um serviço secundário de TV a cabo - um território nacional em questão de horas. O protocolo de internet (IP) destruiu o mito do regionalismo da televisão - e de que havia obstáculos desafiadores em criar uma rede de televisão. (WOLFF, 2015, p. 88).

Como observado por Mcdonald e Smith-Rowsey (2016), a Netflix apresenta uma imagem inovadora e subversiva na indústria da televisão que se apoia no sucesso da sua programação original. Não é de se estranhar tal afirmação, visto que nos últimos anos o investimento em produções exclusivas é expressivo. Só em 2018, a empresa desembolsou cerca de três bilhões dólares para financiar conteúdo e marketing, a estratégia se manteve para os anos seguintes, embora os executivos estejam buscando rever os orçamentos, utilizando os recursos em apostas mais assertivas e que possam gerar maior retorno em audiência e capital simbólico para a empresa, resultando em um maior número de assinantes. $^{7}$

Wolff (2015, p. 92) ressalta a importância das narrativas como um ponto em comum entre o modelo da televisão tradicional e o modelo novo representado pela Netflix, afirmando que "nenhum software será capaz de criar comédias e dramas para a televisão". Não é só o meio televisivo que se vê em discussões acerca da atuação de empresas como

\footnotetext{
7 Pode-se dizer que a estratégia de oferta de conteúdo da Netflix depende de dados, variedade e volume de títulos, o que faz com que a empresa não apenas lance muitos produtos, como também cancele uma quantidade considerável, por não ter a audiência desejada. A empresa demonstra interesse então em investir em produtos que possam se tornar hits, como os filmes "O Irlandês" e "História de Um Casamento", que contaram com reconhecidos diretores, como Martin Scorsese e Noah Baumbach, além de elenco de atores premiados. Tomando cuidado para não deixar de lado a segmentação característica nas produções da empresa. Ambos os movimentos podem ser explicados por Anderson (2006), através da Teoria da Cauda Longa.
} 
a Netflix nos últimos anos que o embate entre a indústria do cinema e o mercado do streaming tomou forma. Além das produções seriadas, a Netflix também direciona seus recursos para a produção de filmes, assim, é natural que a empresa busque reconhecimento também para seus produtos neste formato. Entretanto, para que pudesse chegar em espaços tradicionalmente ocupado por estúdios de cinema, como festivais e premiações, os títulos da empresa de vídeo on-demand deveriam atender a requisitos, como exibir seus filmes em salas de cinema. Assim, a Netflix passou a exibir alguns de seus filmes em salas durante um curto período de tempo, para posteriormente disponibilizá-los para sua base de assinantes, gerando atrito com os proprietários das redes de cinema por gerar baixas arrecadações devido ao pouco tempo de exibição.

Desta forma, após conseguir consolidar suas obras em premiações voltadas a produtos televisivos, a Netflix alcançava um novo estágio: ter suas obras indicadas nas categorias principais de festivais e premiações de cinema, como o Oscar. Em 2019, "Roma" alcançou 10 indicações e ganhou três estatuetas do Oscar. Já em 2020, a empresa concorreu com títulos como "O Irlandês" e "História de Um Casamento", o primeiro arrematou dez indicações, mas saiu de mãos vazias, enquanto o segundo foi indicado a seis categorias e faturou apenas uma, a de Melhor Atriz Coadjuvante para Laura Dern.

A posição galgada pela empresa na última década trouxe mudanças no mercado audiovisual com a entrada de concorrentes importantes, tais como as plataformas de streaming Amazon Prime, Apple+, Disney+ e a plataforma que contará com conteúdo do grupo Warner Media, incluindo os títulos da DC Comics, Warner Bros e HBO. A última, em especial, é uma concorrente já observada de perto pela Netflix, como expressado pelo diretor de conteúdo da empresa, Ted Sarandos, em artigo para a GQ Magazine em que dizia que "o objetivo é se tornar a HBO mais rápido do que a HBO pode se tornar nós". ${ }^{8}$

Sem deixar de lado as particularidade de cada empresa e dos modelos utilizados, é possível dizer que, nos anos seguintes, a Netflix ao menos alcançou a posição de competir com a HBO, com um catálogo original com títulos como "The Crown", "Ozark" e "La Casa de Papel", sendo a terceira uma das recordistas de audiência na plataforma mundialmente, ressaltando outro traço observado nos últimos anos nas pro-

$\overline{8}$ "The goal is to become HBO faster than HBO can become us." (tradução nossa). 
duções da Netflix: a regionalização de sua produção, observada também em obras como "Coisa mais Linda" (Brasil) e "Vagabond" (Coreia do Sul), dentre outros.

\section{Considerações finais}

Ao longo das décadas, o campo do entretenimento audiovisual foi submetido a mudanças em sua dinâmica de funcionamento, a partir da ressignificação de lógicas de produção vigentes, além da consolidação de novos modelos de distribuição e particularidades dos mesmos. Neste aspecto, as trajetórias de HBO e Netflix evidenciam a necessidade dos agentes que compõem o campo midiático de estarem atentos às forças que movimentam este espaço dos possíveis levando em consideração aspectos como a cultura digital, novos modelos de negócio e o trabaIho criativo como estratégia para angariar capitais. No estado atual do campo, o modelo tradicional, representado neste trabalho pela HBO, é vigente e orienta em grande medida as práticas de produção e consumo neste campo - uma vez que a empresa ocupa uma posição a partir da qual é capaz de ditar regras do jogo. O que a trajetória ascendente da Netflix indica, por outro lado, é que este modelo pode estar ameaçado por uma outra lógica de operação, que poderá vir a se tornar predominante.

Pode-se dizer então que a trajetória da Netflix no campo de produção audiovisual, por um lado, força este espaço a se reorganizar, redistribuindo capitais e alterando posições e, por outro, parte de um conjunto de possíveis anteriormente sedimentados por empresas como a HBO, sobretudo no que diz respeito a uma cultura de produção orientada para a quality TV e no modelo de faturamento baseado em assinaturas, a despeito das diferenças entre os padrões tecnológicos de streaming e broadcasting.

No que tange ao modelo de negócios e às formas de comunicação mercadológica, é mister notar que ambas procuram, cada uma a sua forma e em adequação ao estado do campo em que se inserem historicamente, distinguir-se da concorrência, marcando posições diferenciais e, por isso, ascendendo a lugares de poder e reconhecimento no interior do campo da produção audiovisual. 


\section{REFERÊNCIAS}

ALVES, Soraia. Mais uma vez, Netflix sai do Oscar com poucos vencedores apesar de muitas indicações. B9, 10 de fev. 2020. Disponível em: <https://www.b9.com.br/121268/mais-uma-vez-netflix-sai-do-oscar-com-poucos-vencedores-apesar-de-muitas-indicacoes/> Acesso em: 20 de mai. 2020

ANDERSON, Chris. A Cauda Longa. Rio de Janeiro: Editora Campus, 2006.

BIANCHINNI, Maíra. 'NÃO É TV' - ESTRATÉGIAS COMUNICACIONAIS DA HBO NO CONTEXTO DAS REDES DIGITAIS. Santa Maria: UFSM, 2011. Disponível em: <http://repositorio.ufsm.br/ handle/1/6322>. Acesso em: 25 set. 2017.

BOURDIEU, Pierre. As Regras da Arte. 1a Ed. São Paulo: Companhia das Letras, 1992.

BOURDIEU, Pierre. Razões Práticas: Sobre a teoria da ação. Campinas: Ed. Papirus, 1996.

BROWN, Tracy. HBO wins more Emmys than Amazon and Netflix. Los Angeles Times, 22 de set. 2019. Disponível em: <https://www.latimes.com/entertainment-arts/tv/story/2019-09-22/emmys-hbo-netflix-amazon-battle>. Acesso em: 20 de mai. 2020

CARVALHO, Bruno. Netflix confima o cancelamento de Girlboss (e talvez seu erro na compra desenfreada de conteúdo original). Ligado em Série, local desconhecido, 25 jun. 2017. Disponível em: <https://www.ligadoemserie.com.br/2017/06/netflix-confirma-o-cancelamento-de-girlboss-e-talvez-seu-erro-na-compra-desenfreada-de-conteudo/ >. Acesso em 08 fev. 2020.

COLETTI, Caio. HBO e Netflix empatam em número de vitórias no Emmy 2018. UOL, 18 de set. 2019. Disponível em <https://entretenimento.uol.com.br/noticias/redacao/2018/09/18/hbo-e-netflix-empatam-em-numero-de-vitorias-no-emmy-2018.htm>. Acesso em: 18 de mai. 2020

DA SILVA, Rafael Rodrigues. MPAA revela que número de assinantes de streaming é maior do que os de TV a cabo. Canaltch, 22 de mar. 2019. Disponível em: <https://canaltech.com.br/ entretenimento/mpaa-revela-que-numero-de-assinantes-de-streaming-e-maior-do-que-os-de-tv-a-cabo-135447/>. Acesso em: 18 de mai. 2020.

ECO, U. A inovação no seriado. In: Sobre espelhos e outros ensaios. Rio de Janeiro: Nova Fronteira, 1989.

EDGERTON, Gary R. A Brief History of HBO. In: EDGERTON, Gary R.; JONES, Jeffrey P. (orgs.). The Essential HBO Reader. Lexington: The University Press of Kentucky, 2008.

EQUIPE TECMUNDO. Como a análise de dados na Netflix construiu o sucesso da empresa?. Tecmundo, 14 de jun. 2018. Disponível em: <https://www.tecmundo.com.br/internet/131307-analise-dados-netflix-construiu-sucesso-empresa.htm> Acesso em: 20 de mai. 2020

ESQUENAZI, Jean Pierre. As Séries Televisivas. 1a Ed. Lisboa: Texto e Grafia, 2011.

FLORIDA, Richard. A ascensão da classe criativa: e seu papel na transformação do trabalho, lazer, comunidade e cotidiano. Tradução de Ana Luiza Lopes. Porto Alegre: L\&PM Editores, 2011.

HANCOCK, Alice. Em disputa entre cinemas e streaming, presidente de cadeia de salas culpa Netflix. Financial Times, 26 de dez. 2019. Disponível em: <https://www1.folha.uol.com.br/ilustrada/2019/12/em-disputa-entre-cinemas-e-streaming-presidente-de-cadeia-de-salas-culpa-netflix. shtml>. Acesso em: 19 de mai. 2020 
HASS, Nancy. And the Award for the Next HBO Goes to....GQ Magazine, 29 de jan. 2013. Disponível em: <https://www.gq.com/story/netflix-founder-reed-hastings-house-of-cards-arrested-development>. Acesso em: 18 de mai. 2020.

HOLPUCH, Amanda. Netflix makes history as House of Cards takes top Emmy nominations. The Guardian, Nova York, 18 de jul 2013. Disponível em: <https://www.theguardian.com/tv-and-radio/2013/jul/18/emmys-nominations-netflix-house-of-cards> Acesso em: 08 de fev. 2020.

JENKINS, Henry. Cultura da Convergência. Editora Aleph, 2008.

JENKINS, Henry; FORD, Sam; GREEN, Joshua. Cultura da conexão: criando valor e significado por meio da mídia propagável. São Paulo: Aleph, 2014.

KELSO, Tony. And now no word from our sponsors: How HBO puts the risk back into television. In: LEVERETTE, Marc; OTT, Brian L.; BUCKLEY, Cara Louise. IT'S NOT TV: WATCHING HBO IN THE POST-TELEVISION ERA. New York: Routledge, 2008.

LUIZ, André. Netflix deve repensar o alto orçamento de suas produções originais. Tecmundo, 03 de jul. 2019. Disponível em: <https://www.tecmundo.com.br/mercado/143361-netflix-deve-repensar-alto-orcamento-producoes-originais.htm>. Acesso em 18 de mai. 2020

McCABE, Janet; AKASS, Kim. It's not TV, it's HBO original programming: producing quality TV. In: LEVERETTE, Marc; OTT, Brian L.; BUCKLEY, Cara Louise. IT'S NOT TV: WATCHING HBO IN THE POST-TELEVISION ERA. New York: Routledge, 2008.

MCDONALD, Kevin; SMITH-ROWSEY, Daniel. The Netflix Effect: Technology and Entertainment in the 21st Century. New York: Bloomsbury Academic, 2016. Disponível em: <https://books.google. com.br/books?id=ng9NDAAAQBAJ\&printsec=frontcover\&hl=pt-BR\&source=gbs_ge_summary_r\&ca$\mathrm{d}=0 \# \mathrm{v}=$ onepage $\& \mathrm{q} \& \mathrm{f}=\mathrm{false}>$. Acesso em: 18 de mai. 2020

MITTEL, J. Narrative Complexity in Contemporary American Television. In.: Velvet Light Trap, Volume 58, pp.29-40, University of Texas Press, 2006.

MURRAY, Janet. Hamlet no Holodeck - O futuro da narrativa no Ciberespaço. São Paulo: Itaú Cultural: Unesp, 2013.

SANTAELLA, Lúcia. CULTURA DAS MíDIAS. São Paulo. 1992.

SANTAELLA, Lúcia. Da Cultura das Mídias à Cibercultura: $\mathbf{O}$ advento do pós-humano. Revista FAMECOS, Porto Alegre, no 22, dez. 2003.

SANTA ROSA, André. Em crescimento, serviços de streaming provocam mudanças no mercado audiovisual. Diário de Pernambuco, 01 de abr de 2020. Disponível em: <https://www.diariodepernambuco.com.br/noticia/viver/2020/04/em-crescimento-servicos-de-streaming-provocam-mudancas-no-mercado-aud.html>. Acesso em: 19 de mai. 2020

SANTO, Avi. Para-television and discourses of distinction: the culture of production at HBO. In: LEVERETTE, Marc; OTT, Brian L.; BUCKLEY, Cara Louise. IT'S NOT TV: WATCHING HBO IN THE POST-TELEVISION ERA. New York: Routledge, 2008.

SERJEANT, Jill. 'Game of Thrones' quebra recordes de audiência na TV e deixa fãs tristes e enfurecidos. Folha de São Paulo, 20 de mai. 2019. Disponível em: <https://f5.folha.uol.com.br/ cinema-e-series/2019/05/game-of-thrones-quebra-recordes-de-audiencia-na-tv-e-deixa-fas-tristes-e-enfurecidos.shtml?cmpid=assmob\&origin=folha $>$. Acesso em: 18 de mai. 2020 
SOUZA, Maria Carmem Jacob. Campo da telenovela e autoria: notas sobre a construção social do poder do escritor nas telenovelas brasileiras. In: V Encontro Latino de Economia Política da Informação, Comunicação e Cultura. Salvador, 2005.

TAURION, Cezar. Big Data. Rio de Janeiro: Brasport, 2013. Epub

VAN DIJCK, José; POELL, Thomas; DE WALL, Martijn. The plataform society: public values in a connective word. Oxford University Press: Nova lorque, 2018.

WOLFF, Michael. Televisão é a nova televisão: 0 trunfo da velha mídia na era digital. Tradução: Ana Paula Corradini, Guilherme Miranda, Luiza Leal da Cunha, 1. Ed. São Paulo: Globo, 2015.

Data do recebimento: 14 fevereiro 2020

Data da aprovação: 11 junho 2020 


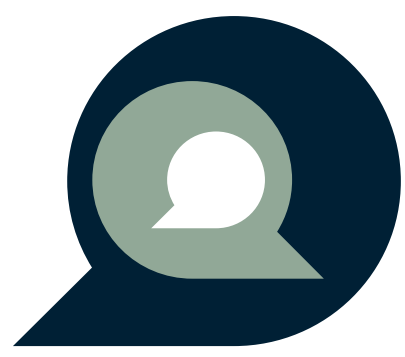

